\title{
Vowel acoustics reliably differentiate three coronal stops of Wubuy across prosodic contexts
}

\author{
RIKKE L. BUNDGAARD-NIELSEN ${ }^{a}$, BRETT J. BAKER ${ }^{b}$, CHRISTIAN KROOS $^{a}$, \\ MARK HARVEYc and CATHERINE T. BESTTa,d \\ aMARCS Auditory Laboratories, University of Western Sydney \\ ${ }^{b}$ School of Languages and Linguistics, University of Melbourne \\ 'School of Humanities and Social Science, University of Newcastle \\ ${ }^{d}$ Haskins Laboratories, New Haven
}

\section{Abstract}

The present study investigates the acoustic differentiation of three coronal stops in the indigenous Australian language Wubuy. We test independent claims that only $V C$ (vowel-into-consonant) transitions provide robust acoustic cues for retroflex as compared to alveolar and dental coronal stops, with no differentiating cues among these three coronal stops evident in CV (consonant-into-vowel) transitions. The four-way stop distinction |t, $t, t, c /$ in Wubuy is contrastive word-initially (Heath 1984) and by implication utterance-initially, i.e., in CV-only contexts, which suggests that acoustic differentiation should be expected to occur in the $C V$ transitions of this language, including in initial positions. Therefore, we examined both $V C$ and $C V$ formant transition information in the three target coronal stops across VCV (word-internal), V\#CV (word-initial but utterance-medial) and \#\#CV (word-and utterance-initial), for /a/ vowel contexts, which provide the optimal environment for investigating formant transitions. Results confirm that these coronal contrasts are maintained in the CVS in this vowel context, and in all three positions. The patterns of acoustic differences across the three syllable contexts also provide some support for a systematic role of prosodic boundaries in influencing the degree of coronal stop differentiation evident in the vowel formant transitions.

\section{Introduction}

The multiple coronal place distinctions in 'coronal-rich' languages pose a unique set of problems for their speakers and listeners. They must fine-tune their speech production system to produce, and their perceptual systems to perceive, very subtle differences in place of articulation for the different coronal closures, and in the tongue tip movements into and out of those closures. Examining the acoustic correlates of these coronal contrasts, therefore, is deeply important in terms of testing phonological theory, investigating the phonetics-phonology interface, and 
understanding how children (or adults) acquiring such languages could learn to both perceive and produce these fine-grained distinctions. It is also essential to efforts to revitalize such languages, given the difficulty that coronal stop place distinctions often pose for learners whose first languages have fewer coronals (see, for instance, Werker et al. 1981; Werker and Lalonde 1988, on English listeners' difficulty with Hindi dental-retroflex place distinctions).

Coronal consonants are produced with the anterior portion of the tongue (tip/blade) at different places of articulation (POA) in the general dental/alveolar region, within a given consonant manner-class (i.e., stops, nasals, liquids). A coronal series in a coronal-rich language may include three or all four of the following: alveolar /t/, dental /t/, retroflex /t/, palatal /c/. Coronal-rich languages are rare, particularly those that have a four-way stop POA contrast. Many Indigenous Australian languages fall in that set, and most of them employ multiple coronal POAs not only in their stops but also in their nasal consonant series, and commonly in their lateral series as well. By contrast, the great majority of the world's languages differentiate their stops on a grosser scale, typically contrasting only velar (tongue back), alveolar (tongue tip) and labial (lips) stops, in series such as $/ \mathrm{k} \mathrm{t} \mathrm{p/} \mathrm{and}$ /g d b/ (Ladefoged and Maddieson 1996; Maddieson 1997; Ladefoged 2001).

It remains unclear how native speakers of coronal-rich languages differentiate multiple coronal stops acoustically. Various measures related to both spectral and temporal properties, especially the place of articulation information carried on preceding and following vowels, have been suggested to contribute to this differentiation (see, for instance, Tabain 2003a). But few systematic studies have specifically examined the acoustic correlates of multiple within-language distinctions in coronal stop POA, and the data reported to date remain incomplete and inconclusive, as discussed below.

Thus, our primary aim is to better understand the acoustic distinctions between multiple coronal stops, specifically in terms of vowel formant transitions into and out of the consonants. Coronal stops have been claimed to exhibit high resistance to coarticulation (Tabain and Butcher 1999; Butcher and Tabain 2004) and, conversely, to exert strong acoustic effects on neighbouring vowels, in particular the open/low vowel /a/, which also provides the largest tongue/jaw excursion from that for a coronal stop (Recasens and Espinosa 2009). Therefore, formant transitions into and out of the vowel /a/ may provide the clearest and most systematic, reliable information about coronal place distinctions in coronal-rich systems. For these reasons, we examined the vowel transitions of dental, alveolar and retroflex coronal stops in /a/-contexts as produced by several native speakers of the Australian Indigenous language Wubuy (also known as 'Nunggubuyu' [Heath 1984]). Wubuy ['wobur] is a highly endangered language with the even rarer trait of maintaining a full four-way coronal stop distinction across a variety of prosodic positions and in three vowel contexts, including /a/.

The stop POAs of coronal-rich languages are typically subdivided into apicals, for which the primary articulator is the tongue tip, and laminals, for which the 
tongue blade is the primary articulator. In those with 3- or 4-way coronal place contrasts, such as Wubuy, the apical versus laminal distinction generally leads to a subdivision of the coronals into an apical sub-class consisting of alveolars and retroflexes, and a laminal subclass consisting of dentals and alveo-palatals. It has been posited that tongue tip constriction orientation is up for apicals and down for laminals (Browman and Goldstein 1989), or that tongue tip posture is neutral for alveolar, up and tilted backward for retroflex, up for dental, and down for alveopalatal (Butcher 1993). Further, the retroflex stop articulation has been reported to involve a forward-sweeping gesture of the sublaminal surface of the tongue tip (see for instance electropalatography findings in Butcher 1993, and Henderson 1998). A recent electromagnetic articulometry (EMA) study with Wubuy speakers (Best et al. 2010) found experimental support for the apical versus laminal subdivision. The authors suggested that laminals are characterised by a forward thrust of tongue-tip and tongue body, whereas apicals are characterised by tongue body stabilization and tongue-tip extension, and that the two-way contrasts within each subclass result from additional differences in tongue-tip kinematics (cf also Anderson 2000).

Despite these detailed articulatory descriptions, we lack systematic evidence to date regarding the acoustic correlates of the proposed gestural distinctions among the coronal POAs that are thought to pose the greatest difficulties: dental, alveolar and retroflex. The three-way distinction among dental, alveolar and retroflex stops in Wubuy has previously been shown to possess very small acoustic differences (Ladefoged 2001: 158).

One of the indications that these three coronal stops are difficult to distinguish in production and perception is that they are commonly neutralised in certain contexts, particularly word-initially (e.g. Steriade 2001; Hamann 2003). The existing literature on multiple coronal contrasts, principally from Australian but also from Dravidian languages such as Tamil and Malayalam, reports two common patterns of neutralisation of coronal contrasts, namely that between alveolars and dentals, and that between alveolars and retroflexes (see, for instance, Dixon 1980; Dart 1991; Dart and Nihilani 1999; Hamilton 1996; Anderson 1997, 2000; Steriade 2001). It has been generally assumed that these neutralisations arise from the degree of acoustic overlap and/or similarities between these stop consonants. Further, this has been suggested as the reason for an observed asymmetry in the perceptibility of apical coronal contrasts in / VC/ versus /CV/ contexts (Steriade 2001).

There is some historical evidence for neutralisation between dentals and both apicals in utterance and/or word-initial position (i.e., consonant-vowel /CV/ onsets) in a number of Australian languages (Harvey 2003). In the case of alveolars versus dentals, it has been claimed that their CV "formant transitions ... are essentially identical and cannot be used to distinguish them" (Hamilton 1996: 51, citing Bradley 1980; Evans 1985). The alveolar-retroflex contrast is also commonly reported to neutralise in initial position and following non-apical consonants 
(see Dixon [1980], Hamilton [1996] for general surveys of this pattern in Australian languages). In short, these neutralizations seem to occur where no POA information is available from a preceding vowel. For perceiving these coronal distinctions, particularly the alveolar-retroflex contrast, it is thought that listeners must rely on the information from the preceding vowel's F3, which is reportedly lower and reflects a more posterior POA for the retroflex than the alveolar (see e.g., Hamilton 1996; Anderson 1997; Narayanan and Kaun 1999; and Steriade 2001).

The purported failure of CV transition cues to distinguish place of articulation differences between coronal consonants, however, would be at odds with general reports (from studies of non-coronal rich languages) that CV transitions carry substantial information about place of articulation in stop consonants. For instance, it has been suggested that place of articulation information is carried in $\mathrm{F} 2$ transition differences in the following vowel in a /CV/ syllable (e.g., Liberman et al. 1967; Dorman and Loizou 1996; Smits et al. 1996; for a thorough review, see Pickett et al. 1995).

However, despite the fact that it is often claimed that the word-initial apical neutralisation pattern is common to Australian languages, there is a general dearth of acoustic investigations of this phenomenon in individual languages (but see Butcher 1995, who, nonetheless, examines apical-initial words only in citation context). Furthermore, a small number of Australian languages, including Wubuy, are reported to maintain all coronal contrasts even in word-initial position (Heath 1984), suggesting that the observed patterns of neutralisation of apical contrasts in initial position are not universal, but are in fact language specific.

The Wubuy phonemic inventory (see Table 1: based on Heath 1984) is typically Australian - 'long and flat' (Tabain and Butcher 1999) - characterised by many place distinctions (labial, dorsal, and four coronal places of articulation) but few manner distinctions. The Wubuy 4-way coronal stop series consists of /t, t, t, c/, traditionally categorised according to the primary articulator as two apicals (the alveolar $/ \mathrm{t} /$ and retroflex $/ \mathrm{t} /$ ), and two laminals (the dental $/ \mathrm{t} /$ and alveo-palatal $/ \mathrm{c} /$ ).

According to Heath (1984: 12), the contrasts between $/ \mathrm{t} /$ and $/ \mathrm{t} /$, on the one hand, and between $/ \mathrm{t} /$ and $/ \mathrm{t} /$, on the other, are maintained in word-initial as well as word-medial position in Wubuy. Presumably, speakers must therefore differentiate these stops using place information from various sources. Information about POA could include differences in the formant transitions of any preceding or following vowel, and/or differences in the temporal and/or spectral qualities of the consonant release bursts. In particular, spectral and temporal characteristics of the release bursts do indeed differentiate Wubuy dental, alveolar and retroflex stops across different prosodic contexts (Bundgaard-Nielsen, Baker et al. 2010). This study, however, also found that the dental vs. alveolar and alveolar vs. retroflex contrasts appear to be more 'fragile' in the sense of having fewer significantly distinct acoustic cues, particularly in utterance-initial position.

Other prior research, in addition, has suggested that the release bursts may play less of a role in differentiating Wubuy coronal stops than do the formant transi- 
tions. According to acoustic data collected from a single speaker and presented in Ladefoged (2001), the four coronal stops of Wubuy are set apart primarily by the formant transitions leading into and out of the consonants (i.e., in preceding and following vowels), and only by very subtle differences in the burst noise. According to that report, dental $/ \mathrm{t} /$ has a slightly higher burst frequency than alveolar $/ \mathrm{t} /$, while the difference in burst frequency between / $/$ and the retroflex / $/$ / is reportedly almost non-existent, with the majority of place-information carried on the preceding vowel (if present). The lamino-palatal /c/ is characterised by a burst that has a lower frequency, and remains relatively high in intensity for a longer period, than the other three Wubuy coronal stops.

Finally, other recent data on the temporal characteristics of Wubuy coronal stop closures indicate that the stops differ across prosodic contexts in terms of the duration of the relatively stable 'hold' phase of the stop relative to the duration of the entire consonant gesture (Bundgaard-Nielsen, Kroos et al. 2010). According to that study, which examined the four stops in $/ \mathrm{iCi} /, / \mathrm{aCa} /$, and $/ \mathrm{uCu} /$ contexts, the retroflex stop exhibits a significantly shorter closure period relative to the other coronal stop places. Furthermore, the two apical stops (alveolar and retroflex), considered together, had shorter relative consonant nucleus durations than the two laminal stops (dental and palatal).

Coronal stops in Wubuy thus offer a unique opportunity to investigate the differentiation of fine coronal contrasts, including examination of the claims that the most robust cues that differentiate retroflex stops (and nasals and laterals) from alveolar and dental stops exist in the VC transition, and not in the CV transition. In this study, we examined the vowel acoustics into and out of the Wubuy coronal stops across three prosodic contexts: /aCa/, /a\#Ca/, and /\#\#Ca/. The three prosodic contexts we examine here allow us to compare the relative contributions of vowel transitions into and out of the consonant to the assumed maintenance of segmental contrasts in coronals across positional contexts. This has not been possible in prior studies of languages for which the apical stop contrast is known to be neutralised in word- and especially utterance-initial positions. Further, the differences in the vowel transitions in the three prosodic contexts allow us to make inferences about differences in the gestures involved in the formation of coronal stops. Such differences in turn may be assumed to be relevant to their phonological behaviour more generally in patterns of neutralisation, both synchronically and diachronically.

\section{Method}

\subsection{Wubuy}

Wubuy is an endangered Indigenous Australian language spoken in Eastern Arnhem Land. It is the first language for adults over the age of around 45 in the community of Numbulwar, and is their primary means of communication with each 
Table 1. The consonant inventory of Wubuy, adapted from Heath (1984).

\begin{tabular}{lcccccc}
\hline & Labial & $\begin{array}{c}\text { Lamino- } \\
\text { dental }\end{array}$ & $\begin{array}{l}\text { Apico- } \\
\text { alveolar }\end{array}$ & $\begin{array}{l}\text { Apico-post- } \\
\text { alveolar (retroflex) }\end{array}$ & $\begin{array}{l}\text { Lamino- } \\
\text { alveopalatal }\end{array}$ & $\begin{array}{l}\text { Dorso- } \\
\text { velar }\end{array}$ \\
\hline Stop & $\mathrm{p}$ & $\mathrm{t}$ & $\mathrm{t}$ & $\mathrm{t}$ & $\mathrm{c}$ & $\mathrm{k}$ \\
Nasal & $\mathrm{m}$ & $(\mathrm{n})$ & $\mathrm{n}$ & $\mathrm{n}$ & $\mathrm{n}$ & $\mathrm{j}$ \\
Lateral & & $\mathrm{n}$ & $\mathrm{l}$ & $\mathrm{l}$ & & \\
Tap/trill & & & $\mathrm{r}$ & $\mathrm{t}$ & $\mathrm{j}$ & \\
Approx. & $\mathrm{w}$ & & & & &
\end{tabular}

other. Children are no longer acquiring Wubuy as a first language, and people under the age of 45 have varying degrees of command of the language. Instead, their primary means of communication is Kriol, the local vernacular (an Englishlexified creole; see Sandefur 1979; Harris 1986; Munro 2005). There are also both first and second language users of Wubuy in other communities, particularly in Groote Eylandt, but also in Darwin. There are currently perhaps 60 fluent first language speakers of Wubuy.

Phonologically, Wubuy resembles the neighbouring Yolngu languages in having a four-way coronal place distinction in stops $-/ \mathrm{t}, \mathrm{t}, \mathrm{t}, \mathrm{c} /$. According to Heath (1984), who wrote the major grammar of the language, the four-way coronal series is contrastive both word-medially and word-initially (see Table 1 for the full consonant inventory of Wubuy). As summarised earlier, it is claimed that the apical contrast (i.e., alveolar vs. retroflex) is difficult to perceive in the absence of a preceding vowel (Heath 1984), ${ }^{1}$ but Wubuy is one of the few Australian languages said to maintain a contrast in this position (Hamilton 1996). Wubuy has a typical Australian three vowel inventory of /a, i, u/ (Heath 1984). Vowel length is also contrastive according to Heath (1984), but as he notes there, and in agreement with the experience of the second author, duration may or may not be a consistent correlate of the phonological length distinction.

We have used voiceless symbols in the phonetic representations of the stops throughout this paper, consistent with Australianist transcription conventions. Voicing is non-contrastive in Wubuy, as in most Australian languages, and the actual VOT of stops varies allophonically according to context.

\subsection{Participants}

We recorded three female native speakers (ages 51-61 years), born and raised in the Numbulwar area by parents and family who were native speakers of Wubuy. ${ }^{2}$ Two participants also reported speaking the neighbouring Aboriginal language Anindilyakwa (of Groote Eylandt: Stokes 1981; Leeding 1989) with relatives other than their parents (grandparents, in-laws).

All three speakers had acquired English as a second language in a classroom setting. One speaker had acquired English from the age of five when she had 
Table 2. Target words for each context. Note that the orthographic representation (leftmost column for each context) represents the Wubuy spelling conventions, in which the alveolar stop is represented by 'd', the retroflex by underscoring 'd', and the dental by digraph 'dh.' The other columns provide a phonetic transcription of the standard Wubuy pronunciation of the word in IPA, and its English gloss.

\begin{tabular}{|c|c|c|c|c|c|c|}
\hline & \multicolumn{3}{|c|}{ Wordlist for the $/ \mathrm{aCa} /$ context } & \multicolumn{3}{|c|}{ Wordlist for the $/ \mathrm{a} \# \mathrm{Ca} /$ and $/ \# \# \mathrm{Ca} /$ contexts } \\
\hline & Orthography & $I P A$ & Gloss & Orthography & $I P A$ & Gloss \\
\hline dental & madhal & ['mata] & 'leech' & dhawal & ['tawal] & 'coccyx' \\
\hline alveolar & maada & ['ma:ta] & ‘pipe’ & dawal & ['tawal] & 'axe shaft junction' \\
\hline retroflex & mada & ['mata] & 'grass' & danggalgarra & ['tajkal,kara] & 'lancewood' \\
\hline
\end{tabular}

enrolled in school, one from the age of eight, and one participant reported acquiring English from the age of 10. All had at least some basic linguistic training, initially for the purposes of Bible translation activities, but all had developed their expertise beyond that base: they were all involved with the local school and language revitalization efforts.

\subsection{Stimuli}

Each of the three participants produced the target consonants $/ t, t, t /$ in the three prosodic contexts given in (1). The target word list is given in Table 2. Note that the primary stress is on the first syllable of each root word. /c/ was also produced in the VCV context, but is not included in the current study as it has not been reported to pose discrimination difficulties for non-native speakers.

\section{(1) Context 1 Phrase-medial, word-internal /VCV/ targets \\ Context 2 Phrase-medial, word-initial /V\#CV/ targets \\ Context 3 Utterance initial, word-initial $/ \# \# \mathrm{CV} /$ targets}

The participants produced five repetitions of the stops - dental $/ \mathrm{t} /$, alveolar $/ \mathrm{t} /$, and retroflex $/ \mathrm{t} /$ - in real Wubuy words in all three prosodic contexts. The target words and carrier phrases were selected to provide a symmetrical vowel context on either side of the target consonant in the VCV and V\#CV contexts, i.e., /aCa/ and /a\#Ca/. Obviously for the utterance-initial \#\#CV context, there is only the following /a/: /\#\#Ca/. As noted in the Introduction, an /a/ vowel context allows for maximal movement between the low jaw position for the vowel and the higher jaw position for the consonants, thus offering maximally extensive formant transitions that can most clearly reveal POA differences in the $\mathrm{V}(\#) \mathrm{C}$ and $\mathrm{CV}$ formant transitions for the three coronal stops.

We used real words because we could not be sure, given our participant group, that these speakers would produce naturally formed articulations of nonsense 
words. Hence, although the segmental contexts surrounding the VCV sequences investigated were selected to be as similar as possible, some context differences were unavoidable due to the requirement of using known words from the available lexicon (Heath 1982) as targets for the speakers to produce. For the VCV context, all three words have $/ \mathrm{m} /$ in the first syllable, preceding the target stop, but one (/matal/) differs from the other two in having a final / $1 /$ in the second syllable instead of an open syllable ending with vowel /a/. For the $\mathrm{V \# CV}$ and \#\#CV contexts, there is no difference in the preceding environment, which is either zero (utterance-initial target word) or the final syllable of the carrier phrase $(/ \mathrm{na} /)$. The following contexts are identical for two of the three (\#)\#CV words: /wal\#/. The third, (/tankalkara/), has a dorso-velar nasal at the end of the initial syllable, following the target $\mathrm{C}$. These deviations from perfect, phonetically matched environments across all target Cs were unavoidable, especially given the reality that although nouns with initial apical stops (alveolar or retroflex) are attested in Wubuy, they are rare (because of a historical lenition rule targeting initial stops, see Heath 1978). Thus minimal pairs were impossible to obtain from existing documents on the productive lexicon of the language.

In Wubuy, as in most other Australian languages, the primary stress is normally on the first syllable of the root. Consequently, there is no way to avoid the fact that the / VCV/ context differs from the /V\#CV/ and /\#\#CV/ contexts with respect to location of stress in relation to the target consonant. However, there have been no reports of interactions between stress and coronal contrasts in Wubuy, nor, indeed, in other Australian languages, with the exception of the Arandic group (see Henderson 1998).

The target words were embedded in Wubuy carrier phrases, which were chosen so as to minimize coarticulation with the adjacent edges of the carrier phrase. The carrier phrase for the word-medial and word-initial elicitations is given in (2) in both Wubuy orthography and IPA. That used for the utterance-initial elicitations, in (3), is a re-ordering of the same words. Wubuy syntax is reported to be nonconfigurational (Heath 1986), so both carrier phrases are acceptable to native speakers, although there are information structure differences. The phrase form in (3) is a standard focus structure, where the target item is in focus (Heath 1984). Items in focus in Wubuy typically lack a noun class prefix (see Heath 1984; Baker 2008). The phrase form in (2) is more neutral, and in particular, items in this environment can carry an overt noun class prefix.

$\begin{array}{lr}\text { 'nga-yamana } & \text { adaba' } \\ \text { ['ya-jamana } & \text { atapa] } \\ \text { 1sG-say.PRs _ now } & \text { now' }\end{array}$

(3)

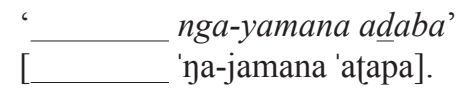




\subsection{Procedure}

The three speakers produced targets in carrier sentences presented in Wubuy orthography on a computer monitor in a fixed order, blocked by the type of consonant. The participants were encouraged to discuss and rehearse the selected words prior to the recording to ensure that all target items were recognized as known words during the recording. During the recording, the participants were instructed to speak in a clear, comfortable voice as though they were speaking to a friend. Five correct utterances (as judged by the speaker herself, as well as by the other speakers who were present in the room during the recording) were recorded for each target, resulting in a total of 45 correct utterances ( 5 tokens $\times 3$ targets in the three contexts). Recordings of targets containing coughs, stutters or speech or reading errors (in particular, utterances involving obvious pausing or hesitation before the target word in the V\#CV context) were discarded.

The sentences and target words were recorded using a Shure SM10A headset cardioid microphone, an EDIROL UA-25 USB audio interface, and a laptop computer with Cool Edit 2000. All recordings had a 16-bit sampling depth with a sampling rate of $44.1 \mathrm{KHz}$. The recordings occurred in a sound-attenuated room at MARCS Auditory Laboratories in Sydney.

\subsection{Acoustic analyses}

A total of five repetitions of each of the 9 target utterances ( 3 in each of the three contexts: $/ \mathrm{aCa} /, \mathrm{a} \# \mathrm{Ca} /$, and $/ \# \# \mathrm{Ca} /)$ containing $/ \mathrm{t}, \mathrm{t}, \mathrm{t} /$ for each of the 3 speakers were included in the analyses, resulting in a total of 135 analysable tokens. All target words were segmented and labelled by two phonetically trained researchers using PraAt acoustic analysis software (Boersma and Weenink 2007) in the following way (see also Figure 1): Onset of the preceding vowel in the $/ \mathrm{aCa} /$ and $\mathrm{la} \# \mathrm{Ca} /$ contexts was defined as the beginning of the first vocal fold pulse in the preceding syllable in which clear formant structure was detectable, and vowel offset was defined as the end of the last vocal fold pulse with clear formant structure. The loss of formant structure thus marked the onset of consonantal closure for the target consonant in those two contexts. Voicing during the closure of the $/ \mathrm{C} /$ was not considered part of the vowel. The release of consonantal closure of the target consonant, identified as the last zero crossing on the waveform before onset of consonantal noise (burst/aspiration), marked the beginning of the Voice Onset interval for all three contexts (including / $\# \# \mathrm{Ca} /$ ). The onset of the following vowel was (as with the preceding vowel) defined as the beginning of the first vocal fold pulse in which clear formant structure was detected, for all three contexts. A random selection of segmented words was checked for consistency of segmentation between the researchers.

Following segmentation of the target words, F1, F2, and F3 values were extracted automatically. In the case of preceding vowels (in the $/ \mathrm{aCa} /$ and $/ \mathrm{a} \# \mathrm{Ca} /$ 


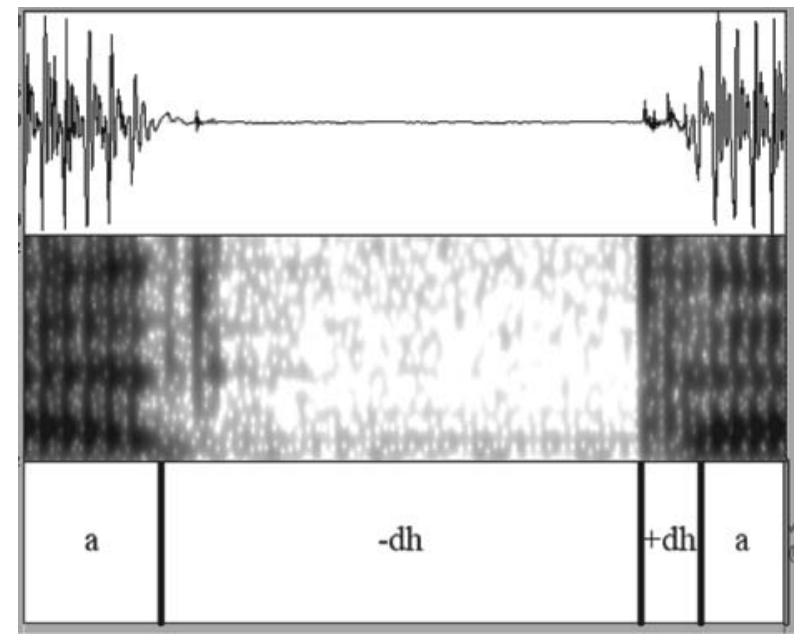

Figure 1. Spectrogram of Wubuy dental stop (|t|) in |a\#Ca| (word initial, sentence medial) context. The period of Closure Duration (CD) is labeled '-dh', while the Voice Onset Time (VOT) is labelled ' $+d h$ '.

contexts), we extracted the formant values at $75 \%$ into the vowel and at consonantal closure. In the case of following vowels, we extracted the formant values at voicing onset and at $25 \%$ into the vowel.

The formant values were estimated using the PrAAT command 'To Formant(burg)'. Time-step was $2.5 \mathrm{~ms}$, maximum number of formants 5 , maximum formant frequency $5 \mathrm{kHz}$, with a $25 \mathrm{~ms}$ window length. Pre-emphasis was from $50 \mathrm{~Hz}$. All extracted vowel measurements were checked by hand if there appeared to be significant changes in formant values during production, or if the values returned by the PraAt script were outside the expected range. Any measurements found to be erroneous were redone by hand using PRAAT.

Mean formant values for these measurements are plotted in Figure 2, showing vowel formant trajectories for the three stops in the three prosodic contexts. Note that there is no preceding vowel trajectory for the \#\#CV context. Numeric values are reported in Table 9 in the Appendix.

Simple visual inspection of these vowel trajectories already suggests apparent differences in the vowel formants preceding the target stops (i.e. in the vowels of $/ \mathbf{a C a} /$ and $/ \mathbf{a} \# \mathrm{Ca} /$ ), consistent with the claims of numerous previous researchers reviewed in the Introduction. What is more surprising is that there are also apparent differences in the following vowel transitions of all three contexts (/aCa/, /a\#Ca/ and /\#\#Ca/). To investigate these apparent differences, we conducted several types of statistical analyses on the acoustic measurements, reported below. 
2(a). /aCa/, Preceding vowel

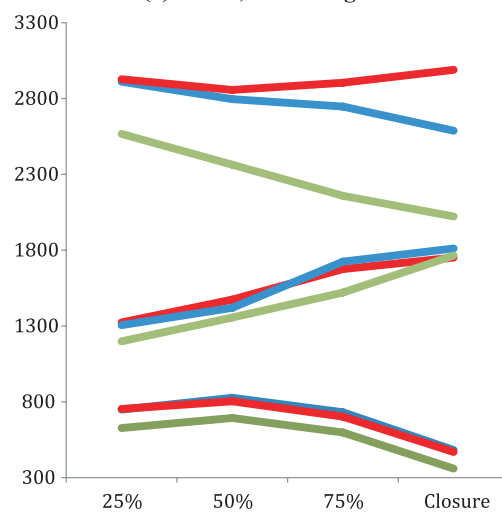

2(c). /a\#Ca/, Preceding vowel

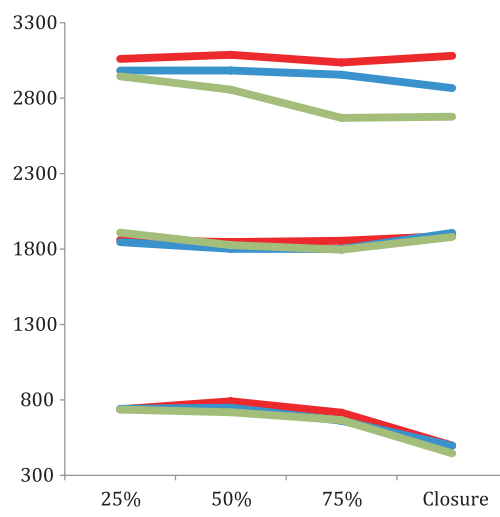

2 (e). /\#\#Ca/, Following vowel

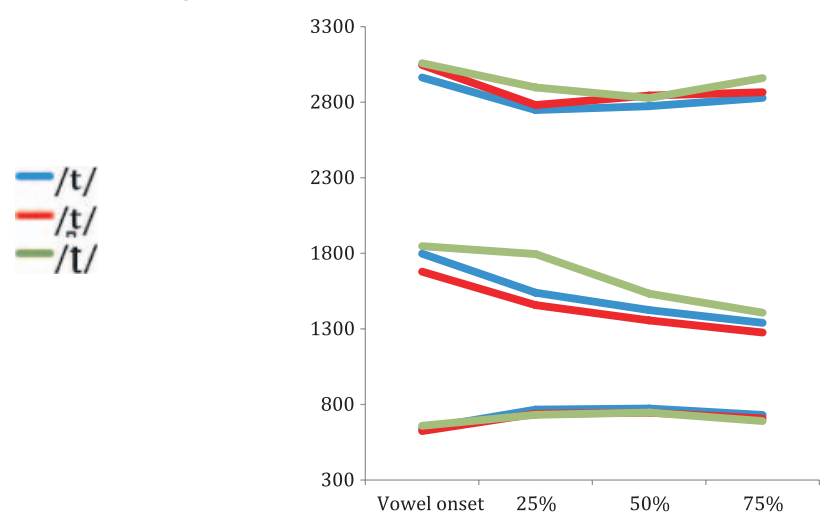

Figure 2. Mean formant trajectories for $/ a /$ preceding and following coronal stops in (a-b) $\mid a C a /$, (c-d) |a\#Ca|, and (e) |\#\#Ca/ contexts. The figures include measurements at the 25\% and $50 \%$ points into the preceding vowel, and at $50 \%$ and $75 \%$ points into the following vowels to provide full pseudo-spectrograms of the vowel transitions on each side of the consonantal constriction period. 


\section{Results}

\subsection{Reduction of the number of variables}

When there is a high number of potentially meaningful dependent variables as in our study, a recommended first step is to investigate whether or not their covariance structure can be exploited to reduce the number of variables used in subsequent statistical analyses. Table 3 shows the correlations between the various formant measures used in this study separated according to their origin from the preceding vowel (upper triangle) or the following vowel (lower triangle).

As can be seen, high correlations (i.e., $>.5$ ) were found only between the two time points for F1 and F3 in the preceding vowel. Thus, the formant measures overall appear to contain little redundancy and most likely cannot be reduced to a smaller set of variables through linear combination. To confirm, we conducted two Principal Component Analyses (PCAs) with the preceding and following vowel measures as respective inputs. The recovered variance per component was 69.3, $11.1,8.5,5.1,4.7$ and $1.3 \%$ for the preceding vowel measures and 46.6, 22.8, 17.7, $7.2,4.2$ and $1.5 \%$ for the following vowel measures. In both cases, the accumulated recovered variance of a minimum of four components would be needed to surpass at least the $90 \%$ mark, which is too close to the original six variables to make worthwhile the added difficulties of interpreting the PCA components, as compared to the original variables. Accordingly, we discuss all data measures in the following sections.

Table 3. Correlations between the formant measures obtained in the preceding and following vowels. The preceding vowel is presented in the upper triangle and the following vowel is presented in the lower triangle.

\begin{tabular}{l|cccccc|c}
\hline & & $\begin{array}{l}75 \% \\
\mathrm{~F} 2\end{array}$ & $\begin{array}{l}75 \% \\
\mathrm{~F} 3\end{array}$ & $\begin{array}{l}\text { Closure } \\
\mathrm{F} 1\end{array}$ & $\begin{array}{l}\text { Closure } \\
\mathrm{F} 2\end{array}$ & $\begin{array}{l}\text { Closure } \\
\mathrm{F} 3\end{array}$ & $\begin{array}{l}\text { Preceding } \\
\text { vowel }\end{array}$ \\
\hline & & 0.07 & 0.29 & 0.61 & 0.01 & 0.33 & $75 \% \mathrm{~F} 1$ \\
Onset F2 & -0.00 & & 0.33 & 0.02 & 0.16 & 0.39 & $75 \% \mathrm{~F} 2$ \\
Onset F3 & 0.17 & -0.08 & & 0.31 & 0.31 & 0.79 & $75 \% \mathrm{~F} 3$ \\
$25 \% \mathrm{~F} 1$ & 0.47 & 0.09 & 0.16 & & -0.02 & 0.24 & Closure F1 \\
$25 \% \mathrm{~F} 2$ & -0.23 & 0.35 & -0.08 & -0.18 & & 0.29 & Closure F2 \\
$25 \% \mathrm{~F} 3$ & -0.25 & -0.24 & 0.42 & 0.04 & 0.16 & & \\
\hline Following & Onset & Onset & Onset & $25 \% \mathrm{~F} 1$ & $25 \% \mathrm{~F} 2$ & & \\
vowel & F1 & F2 & F3 & & & & \\
\hline
\end{tabular}




\subsection{Analysis of the preceding vowel in $/ \mathrm{aCa} /$ and $/ \mathrm{a} \# \mathrm{Ca} /$ context}

Coronal POA differences in the preceding vowel in the $/ \mathrm{aCa} /$ and $/ \mathrm{a} \# \mathrm{Ca} /$ contexts were examined for the F1, F2 and F3 values at $75 \%$ of the vowel and at the point of consonantal closure, via six GLM repeated measures analyses of variance (ANOVAs). Each of the six formant measures served as the dependent variables, and the place of articulation (/t/ vs. /t/ vs. / t $/)$ and prosodic context $(/ \mathrm{aCa} / \mathrm{vs}$. $/ \mathrm{a} \# \mathrm{Ca} /$ ) as within-subject factors. The GLM procedure for each measure included planned contrasts (each pair of consonants within each prosodic context). For all planned comparisons, we applied Mauchley's test of sphericity to consonant, prosodic context and consonant* context interaction. Where sphericity could not be assumed, we adjusted the degrees of freedom accordingly, using the GreenhouseGeisser correction. We also adjusted the alpha for multiple comparisons using Bonferroni correction (from 0.05 to 0.0083 ), which is a conservative approach. Below we discuss the analyses for each formant (F1, F2, and F3) in turn at the two measuring points.

3.2.1. F1 at $75 \%$ and consonantal closure. For F1 at $75 \%$ into the preceding vowel, there was a significant main effect of consonant, $F(2,28)=12.323$, $p<.001$. The effect of prosodic context was non-significant. There was, however, a significant interaction between consonant and prosodic context, $F(2,28)=7.530$, $p=.002$. Planned contrasts (see Table 4 ) showed that F1 significantly differentiated the retroflex $/ \mathrm{t} /$ from both the dental $/ \mathrm{t} /$ and the alveolar $/ \mathrm{t} /$ at $75 \%$ into the preceding vowel in the $/ \mathrm{aCa} /$ context, but it did not differentiate any of the consonant contrasts in the $/ \mathrm{a} \# \mathrm{Ca} /$ context, where the preceding vowel and the wordinitial consonant are separated by a prosodic word boundary.

For $\mathrm{F} 1$ at consonantal closure, there was a marginal main effect of consonant type, $F(2,28)=3.318, p=.051$, while prosodic context failed to reach significance. There was no significant interaction between consonant type and prosodic context. The planned contrast results (see Table 5) were similar to the pattern observed at $75 \%$ into the vowel: F1 significantly differentiated only the retroflex (/t/) from the dental $(/ \mathrm{t} /)$ and the alveolar $(/ \mathrm{t} /)$ at closure in the $/ \mathrm{aCa} /$ context, but did not differentiate any of the consonant contrasts in the $/ \mathrm{a} \# \mathrm{Ca} /$ context.

3.2.2. F2 at $75 \%$ and consonantal closure. For F2 at $75 \%$ into the preceding vowel, the consonant type effect only approached significance, $F(1.325,18.547)=$ $2.869, p=.098$, while there was a strong effect of prosodic context, $F(1,14)=$ $9.474, p=.008$. There was no significant consonant*context interaction. The planned contrast analysis (see Table 4) showed that F2 at $75 \%$ of the preceding vowel did not reliably differentiate $/ \mathrm{t} /$ versus $/ \mathrm{t} /$ versus $/ \mathrm{t} /$ in either the $/ \mathrm{aCa} /$ or /a\#Ca/ context. 
For F2 at consonantal closure, the results indicate that there was no significant main effect of consonant, while again there was a significant main effect of context, $F(1,14)=8.956, p=.01$. There was no significant consonant* context interaction. Planned contrast effects (see Table 5) were similar to those obtained for $\mathrm{F} 2$ at $75 \%$ into the preceding vowel and showed that F2 at consonantal closure does not differentiate / $/$ / versus / $t$ / versus / $/ \mathrm{m} /$ in $/ \mathrm{aCa} /$ or $/ \mathrm{a} \# \mathrm{Ca} /$ context.

3.2.3. F3 at $75 \%$ and consonantal closure. For F3 at $75 \%$ into the preceding vowel, there was a significant main effect of consonant type, $F(1.421,19.891)=$ $76.723, p<.001$, and likewise a significant main effect of prosodic context, $F(1,14)=27.774, p<.001$. There was a significant interaction between consonant type and context, $F(1.385,19.389)=9.653, p=.003$. The results from the planned comparisons (see Table 4) revealed that $\mathrm{F} 3$ at $75 \%$ into the vowel differentiated all three stops (/t/ vs. /t/ vs. / $/ \mathrm{t} /$ ) in the /aCa/ context, but only / t $/$ from $/ \mathrm{t} /$ in the $/ \mathrm{a} \# \mathrm{Ca} /$ context. The $/ \mathrm{t} /$ versus $/ \mathrm{t} /$ difference approached significance, $p=.014$.

For F3 at consonantal closure, the results again show significant main effects of consonant type, $F(2,28)=51.036, p<.001$, and prosodic context, $F(1,14)=$ $80.426, p<.001$, and a significant consonant* context interaction, $F(2,28)=$

Table 4. Results from the planned comparisons for F1, F2, and F3 at 75\% into the preceding vowel for It $t t_{n} /$ in word-medial (|aCa|) and word-initial but utterance-medial (|a\#Ca|) contexts. Significant effects take alpha correction (alpha $=.0083)$ into account, and are indicated in boldface. Marginally significant effects are indicated by *.

\begin{tabular}{|c|c|c|c|c|c|c|c|c|}
\hline Context & Measure & Contrast & $\begin{array}{l}\text { df } \\
\text { error }\end{array}$ & $\mathrm{F}$ & Sig. & $\begin{array}{l}\text { Partial } \\
\text { Eta } \\
\text { Squared }\end{array}$ & $\begin{array}{l}95 \% \text { Conf. } \\
\text { interval } \\
\text { (lower) }\end{array}$ & $\begin{array}{l}95 \% \text { Conf. } \\
\text { interval } \\
\text { (upper) }\end{array}$ \\
\hline \multirow[t]{9}{*}{$/ \mathrm{aCa} /$} & \multirow{3}{*}{ F1_75\% } & $|\mathrm{t}|-|\mathrm{t}|$ & 14 & 1.407 & .255 & .091 & -81.062 & 23.329 \\
\hline & & $|\mathrm{t} /-| \mathrm{t} \mid$ & 14 & 12.767 & .003 & .477 & 41.812 & 167.388 \\
\hline & & $|t /-| t \mid$ & 14 & 29.274 & .000 & .676 & 80.559 & 186.374 \\
\hline & \multirow[t]{3}{*}{ F2_75\% } & $|\mathrm{t}|-|\mathrm{t}|$ & 14 & .952 & .346 & .064 & -58.528 & 156.261 \\
\hline & & $|\mathrm{t} /-| \mathrm{t} \mid$ & 14 & 2.823 & .115 & .168 & -56.407 & 464.274 \\
\hline & & $|\mathrm{t} /-| \mathrm{t} \mid$ & 14 & 1.900 & .190 & .120 & -86.192 & 396.326 \\
\hline & \multirow[t]{3}{*}{ F3_75\% } & $|\mathrm{t}|-|\mathrm{t}|$ & 14 & 10.363 & .006 & .425 & 52.533 & 262.267 \\
\hline & & $|\mathrm{t} /-| \mathrm{t} \mid$ & 14 & 175.217 & .000 & .926 & 624.958 & 866.642 \\
\hline & & $|\mathrm{t} /-| \mathrm{t} \mid$ & 14 & 134.914 & .000 & .906 & 479.750 & 697.050 \\
\hline \multirow[t]{9}{*}{ |a\#Ca/ } & \multirow[t]{3}{*}{ F1_75\% } & $|\mathrm{t}|-|\mathrm{t}|$ & 14 & 6.780 & .021 & .326 & 9.462 & 97.871 \\
\hline & & $|\mathrm{t} /-| \mathrm{t} \mid$ & 14 & 4.205 & .060 & .231 & -2.256 & 100.390 \\
\hline & & $|\mathrm{t} /-/ \mathrm{t}|$ & 14 & .040 & .844 & .003 & -53.726 & 44.526 \\
\hline & \multirow[t]{3}{*}{ F2_75\% } & $|\mathrm{t}|-|\mathrm{t}|$ & 14 & 1.202 & .291 & .079 & -52.069 & 161.002 \\
\hline & & $|\mathrm{t} /-| \mathrm{t} /$ & 14 & 1.686 & .215 & .107 & -38.324 & 155.924 \\
\hline & & $|\mathrm{t} /-| \mathrm{t} \mid$ & 14 & .018 & .896 & .001 & -65.265 & 73.932 \\
\hline & \multirow[t]{3}{*}{ F3_75\% } & $|\mathrm{t} /|-|\mathrm{t}|$ & 14 & 3.121 & .099 & .182 & -17.332 & 179.332 \\
\hline & & $|\mathrm{t} /-| \mathrm{t} \mid$ & 14 & 25.953 & .000 & .650 & 212.645 & 521.888 \\
\hline & & $|\mathrm{t}|-|\mathrm{t}|$ & 14 & 7.840 & $.014^{*}$ & .359 & 66.994 & 505.540 \\
\hline
\end{tabular}


Table 5. Results from the planned comparisons for F1, F2, and F3 at consonantal closure for $/ t \mathrm{t} t \mathrm{t} /$ in word-medial (|aCa|) and word-initial but utterance-medial (|a\#Ca|) contexts. Significant effects take alpha correction (alpha $=.0083)$ into account, and are indicated in boldface.

\begin{tabular}{|c|c|c|c|c|c|c|c|c|}
\hline Context & Measure & Contrast & $\begin{array}{l}\text { df } \\
\text { error }\end{array}$ & $\mathrm{F}$ & Sig. & $\begin{array}{l}\text { Partial } \\
\text { Eta } \\
\text { Squared }\end{array}$ & $\begin{array}{l}95 \% \text { Conf. } \\
\text { interval } \\
\text { (lower) }\end{array}$ & $\begin{array}{l}95 \% \text { Conf. } \\
\text { interval } \\
\text { (upper) }\end{array}$ \\
\hline \multirow[t]{9}{*}{$/ \mathrm{aCa} /$} & \multirow[t]{3}{*}{ F1_closure } & $|\mathrm{t} /-| \mathrm{t} \mid$ & 14 & .235 & .636 & .016 & -70.919 & 44.785 \\
\hline & & $|\mathrm{t} /-| \mathrm{t} \mid$ & 14 & 18.921 & .001 & .575 & 55.525 & 163.541 \\
\hline & & $|\mathrm{t} /-| \mathrm{t} \mid$ & 14 & 65.955 & .000 & .825 & 90.222 & 154.978 \\
\hline & \multirow[t]{3}{*}{ F2_closure } & $|\mathrm{t} /-| \mathrm{t} \mid$ & 14 & .892 & .361 & .060 & -76.277 & 196.277 \\
\hline & & $|\mathrm{t} /-| \mathrm{t} \mid$ & 14 & .660 & .430 & .045 & -76.071 & 168.871 \\
\hline & & $|\mathrm{t} /-| \mathrm{t} \mid$ & 14 & .034 & .856 & .002 & -171.235 & 144.035 \\
\hline & \multirow[t]{3}{*}{ F3_closure } & $|\mathrm{t}|-|\mathrm{t}|$ & 14 & 18.123 & .001 & .564 & 199.201 & 603.732 \\
\hline & & $|\mathrm{t} /-| \mathrm{t} \mid$ & 14 & 195.578 & .000 & .933 & 818.810 & 1115.457 \\
\hline & & $|\mathrm{t} /-| \mathrm{t} \mid$ & 14 & 26.294 & .000 & .653 & 329.067 & 802.266 \\
\hline \multirow[t]{9}{*}{ |a\#Ca/ } & \multirow[t]{3}{*}{ F1_closure } & $|t|-|t|$ & 14 & .001 & .975 & .000 & -98.173 & 101.106 \\
\hline & & $|\mathrm{t} /-| \mathrm{t} \mid$ & 14 & .675 & .425 & .046 & -83.217 & 186.551 \\
\hline & & $|\mathrm{t} /-| \mathrm{t} \mid$ & 14 & .478 & .501 & .033 & -105.499 & 205.899 \\
\hline & \multirow[t]{3}{*}{ F2_closure } & $|\mathrm{t} /-| \mathrm{t} \mid$ & 14 & .450 & .513 & .031 & -83.654 & 43.788 \\
\hline & & $|\mathrm{t} /-| \mathrm{t} \mid$ & 14 & .022 & .885 & .002 & -90.215 & 103.549 \\
\hline & & $|\mathrm{t} /-| \mathrm{t} \mid$ & 14 & .646 & .435 & .044 & -44.407 & 97.607 \\
\hline & \multirow[t]{3}{*}{ F3_closure } & $|\mathrm{t} /-| \mathrm{t} \mid$ & 14 & 25.730 & .000 & .648 & 123.553 & 304.581 \\
\hline & & $|\mathrm{t} /-| \mathrm{t} \mid$ & 14 & 14.209 & .002 & .504 & 173.985 & 633.348 \\
\hline & & $|\mathrm{t}|-|\mathrm{t}|$ & 14 & 2.873 & .112 & .170 & -50.329 & 429.529 \\
\hline
\end{tabular}

10.336, $p<.001$. The planned comparisons (see Table 5) revealed that $\mathrm{F} 3$ at consonantal closure differentiated $/ \mathrm{t} /$ versus $/ \mathrm{t} /$ versus $/ \mathrm{t} / \mathrm{in} / \mathrm{aCa} /$, and $/ \mathrm{t} /$ from $/ \mathrm{t} /$ and $/ \mathrm{t} /$ in the $/ \mathrm{a} \# \mathrm{Ca} /$ context.

\subsection{Analysis of the following vowel in $|\mathrm{aCa}|,|\mathrm{a} \# \mathrm{Ca}|$, and $|\# \# C a|$ contexts}

Coronal consonant and prosodic context differences in F1, F2, and F3 values at voicing onset and at $25 \%$ into the following vowel were also analysed via GLM repeated measures ANOVAs, as described above for analyses of the preceding vowel measures. For planned comparisons, we again used Bonferroni adjustments of alpha (from 0.05 to 0.0055 ).

3.3.1. F1 at voicing onset and $25 \%$ of the following vowel. For F1 at voicing onset of the following vowel, there were significant main effects of consonant type, $F(2,28)=4.720, p=.017$, and prosodic context, $F(1.2000,16.798)=8.632$, $p=.007$, and a significant consonant*context interaction, $F(4,56)=3.196, p=$ .020 . The planned contrasts (see Table 6) showed that F1 at voicing onset of the following vowel only differentiated $/ \mathrm{t} /$ from $/ \mathrm{t} /$ and $/ \mathrm{t} /$ in the $/ \mathrm{aCa} /$ context but did 
Table 6. Results from the planned contrasts for F1, F2, and F3 at vowel onset in the following vowel for $|t| t \mid$ in word-medial (|aCa|), word-initial (|a\#Ca|), and utterance-initial position $(|\# \# C a|)$. Significant effects take alpha correction (alpha $=.0055)$ into account, and are indicated in boldface. Marginally significant effects are indicated by *.

\begin{tabular}{|c|c|c|c|c|c|c|c|c|}
\hline Context & Measure & Contrast & $\begin{array}{l}\text { df } \\
\text { error }\end{array}$ & $\mathrm{F}$ & Sig. & $\begin{array}{l}\text { Partial } \\
\text { Eta } \\
\text { Squared }\end{array}$ & $\begin{array}{l}95 \% \text { Conf. } \\
\text { interval } \\
\text { (lower) }\end{array}$ & $\begin{array}{l}95 \% \text { Conf. } \\
\text { interval } \\
\text { (upper) }\end{array}$ \\
\hline \multirow[t]{9}{*}{ /aCa/ } & \multirow[t]{3}{*}{ F1_onset } & $|\mathrm{t}|-|\mathrm{t}|$ & 14 & 18.926 & .001 & .575 & 36.740 & 108.194 \\
\hline & & $\mid \mathrm{t} /-/ \mathrm{t} /$ & 14 & 3.309 & .090 & .191 & -30.798 & 2.531 \\
\hline & & $|\mathrm{t} /-/ \mathrm{t}|$ & 14 & 22.692 & .000 & .618 & -125.591 & -47.609 \\
\hline & \multirow[t]{3}{*}{ F2_onset } & $|\mathrm{t} /-| \mathrm{t} \mid$ & 14 & 59.063 & .000 & .808 & -337.165 & -190.035 \\
\hline & & $|\mathrm{t} /-| \mathrm{t} \mid$ & 14 & 19.367 & .001 & .580 & -325.731 & -112.269 \\
\hline & & $|t /-| t \mid$ & 14 & .949 & .346 & .063 & -53.581 & 142.781 \\
\hline & \multirow[t]{3}{*}{ F3_onset } & $|\mathrm{t} /-| \mathrm{t} \mid$ & 14 & 13.767 & .002 & .496 & 153.618 & 574.515 \\
\hline & & $|\mathrm{t} /-| \mathrm{t} \mid$ & 14 & 3.027 & .104 & .178 & -41.051 & 393.851 \\
\hline & & $|\mathrm{t} /-/ \mathrm{t}|$ & 14 & 2.217 & .159 & .137 & -457.996 & 82.663 \\
\hline \multirow[t]{9}{*}{ /a\#Ca/ } & \multirow[t]{3}{*}{ F1_onset } & $|\mathrm{t} /-| \mathrm{t} \mid$ & 14 & .002 & .969 & .000 & -63.897 & 66.297 \\
\hline & & $|\mathrm{t} /-| \mathrm{t} \mid$ & 14 & .380 & .548 & .026 & -68.703 & 38.036 \\
\hline & & $|t /-/ t|$ & 14 & .574 & .461 & .039 & -63.318 & 30.251 \\
\hline & \multirow[t]{3}{*}{ F2_onset } & $|\mathrm{t} /-| \mathrm{t} \mid$ & 14 & 5.710 & .031 & .290 & -272.742 & -14.725 \\
\hline & & $|\mathrm{t} /-| \mathrm{t} \mid$ & 14 & 24.479 & .000 & .636 & -231.941 & -91.659 \\
\hline & & $|t /-| t \mid$ & 14 & .073 & .791 & .005 & -161.802 & 125.668 \\
\hline & \multirow[t]{3}{*}{ F3_onset } & $|\mathrm{t} /-| \mathrm{t} \mid$ & 14 & 20.083 & .001 & .589 & 188.124 & 533.476 \\
\hline & & $|\mathrm{t} /-| \mathrm{t} \mid$ & 14 & 42.379 & .000 & .752 & 252.702 & 501.032 \\
\hline & & $|t|-|t|$ & 14 & .024 & .880 & .002 & -208.115 & 240.249 \\
\hline \multirow[t]{9}{*}{ |\#\#Ca/ } & \multirow[t]{3}{*}{ F1_onset } & $|\mathrm{t} /-| \mathrm{t} \mid$ & 14 & .728 & .408 & .049 & -52.714 & 22.714 \\
\hline & & $|\mathrm{t} /-| \mathrm{t} \mid$ & 14 & 3.208 & .095 & .186 & -76.621 & 6.888 \\
\hline & & $|\mathrm{t} /-| \mathrm{t} \mid$ & 14 & .609 & .448 & .042 & -74.474 & 34.741 \\
\hline & \multirow[t]{3}{*}{ F2_onset } & $|\mathrm{t} /-| \mathrm{t} \mid$ & 14 & 8.843 & $.010^{*}$ & .387 & -205.286 & -33.247 \\
\hline & & $|\mathrm{t} /-| \mathrm{t} \mid$ & 14 & 44.647 & .000 & .761 & -222.895 & -114.572 \\
\hline & & $|t /-| t \mid$ & 14 & 1.655 & .219 & .106 & -131.938 & 33.005 \\
\hline & \multirow[t]{3}{*}{ F3_onset } & $|\mathrm{t} /-| \mathrm{t} \mid$ & 14 & 2.351 & .147 & .144 & -33.012 & 198.612 \\
\hline & & $|\mathrm{t} /-| \mathrm{t} \mid$ & 14 & .085 & .775 & .006 & -98.208 & 74.741 \\
\hline & & $|t /-| t \mid$ & 14 & 3.378 & .087 & .194 & -204.843 & 15.776 \\
\hline
\end{tabular}

not differentiate any stops in the two prosodic contexts involving word-initial coronals: /a\#Ca/ and /\#\#Ca/.

For F1 at $25 \%$ into the following vowel, there were main effects of consonant type, $F(2,28)=5.784, p=.008$, and context, $F(2,28)=7.451, p=.003$, as well as a significant consonant*context interaction, $F(4,56)=4.437, p=.003$. The planned contrast (see Table 7) analyses showed that only /t/ versus / $/$ / were differentiated in terms of $\mathrm{F} 1$ at $25 \%$ into the following vowel in the $/ \mathrm{a} \# \mathrm{Ca} /$ context. No other consonant pairings reached significance in any of the three prosodic contexts. 
Table 7. Results from the planned contrasts for F1, F2, and F3 at $25 \%$ into the following vowel for It $t$ t| in word-medial (|aCa|), word-initial (|a\#Ca|), and utterance initial position (|\#\#Ca|). Significant effects take alpha correction (alpha $=.0055)$ into account, and are indicated in boldface. Marginally significant effects are indicated by *

\begin{tabular}{|c|c|c|c|c|c|c|c|c|}
\hline Context & Measure & Contrast & $\begin{array}{l}\text { df } \\
\text { error }\end{array}$ & F & Sig. & $\begin{array}{l}\text { Partial } \\
\text { Eta } \\
\text { Squared }\end{array}$ & $\begin{array}{l}95 \% \text { Conf. } \\
\text { interval } \\
\text { (lower) }\end{array}$ & $\begin{array}{l}95 \% \text { Conf. } \\
\text { interval } \\
\text { (upper) }\end{array}$ \\
\hline \multirow[t]{9}{*}{ /aCa/ } & \multirow[t]{3}{*}{$\mathrm{F} 1 \_25 \%$} & $|\mathrm{t} /-| \mathrm{t} \mid$ & 14 & 6.106 & .027 & .304 & 36.740 & 108.194 \\
\hline & & $|\mathrm{t} /-| \mathrm{t} /$ & 14 & .285 & .602 & .020 & -30.798 & 2.531 \\
\hline & & $|\mathrm{t} /-| \mathrm{t} \mid$ & 14 & 2.524 & .134 & .153 & -125.591 & -47.609 \\
\hline & \multirow[t]{3}{*}{ F2_25\% } & $|\mathrm{t}|-|\mathrm{t}|$ & 14 & 34.766 & .000 & .713 & -337.165 & -190.035 \\
\hline & & $|\mathrm{t} /-| \mathrm{t} \mid$ & 14 & 37.880 & .000 & .730 & -325.731 & -112.269 \\
\hline & & $|\mathrm{t} /-| \mathrm{t} \mid$ & 14 & 1.307 & .272 & .085 & -53.581 & 142.781 \\
\hline & \multirow[t]{3}{*}{ F3_25\% } & $|\mathrm{t}|-|\mathrm{t}|$ & 14 & 9.310 & $.009 *$ & .399 & 153.618 & 574.515 \\
\hline & & $|\mathrm{t} /-| \mathrm{t} \mid$ & 14 & 10.515 & $.006^{*}$ & .429 & -41.051 & 393.851 \\
\hline & & $|\mathrm{t} /-| \mathrm{t} \mid$ & 14 & 3.021 & .104 & .177 & -457.996 & 82.663 \\
\hline \multirow[t]{9}{*}{ la\#Ca/ } & \multirow[t]{3}{*}{ F1_25\% } & $|t|-|t|$ & 14 & 2.175 & .162 & .134 & -63.897 & 66.297 \\
\hline & & $|\mathrm{t} /-| \mathrm{t} /$ & 14 & 3.578 & .079 & .204 & -68.703 & 38.036 \\
\hline & & $|\mathrm{t} /-| \mathrm{t} \mid$ & 14 & 12.905 & .003 & .480 & -63.318 & 30.251 \\
\hline & \multirow[t]{3}{*}{ F2_25\% } & $|\mathrm{t} /-| \mathrm{t} \mid$ & 14 & 2.663 & .125 & .160 & -272.742 & -14.725 \\
\hline & & $|\mathrm{t} /-| \mathrm{t} \mid$ & 14 & 20.271 & .000 & .591 & -231.941 & -91.659 \\
\hline & & $|\mathrm{t} /-| \mathrm{t} \mid$ & 14 & 15.049 & .002 & .518 & -161.802 & 125.668 \\
\hline & \multirow[t]{3}{*}{ F3_25\% } & $|\mathrm{t} /-| \mathrm{t} \mid$ & 14 & 43.820 & .000 & .758 & 188.124 & 533.476 \\
\hline & & $|\mathrm{t} /-| \mathrm{t} \mid$ & 14 & 22.399 & .000 & .615 & 252.702 & 501.032 \\
\hline & & $|\mathrm{t} /-| \mathrm{t} \mid$ & 14 & 3.900 & .068 & .218 & -208.115 & 240.249 \\
\hline \multirow[t]{9}{*}{ /\#\#Ca/ } & \multirow[t]{3}{*}{ F1_25\% } & $|\mathrm{t} /-| \mathrm{t} \mid$ & 14 & 5.921 & .029 & .297 & -52.714 & 22.714 \\
\hline & & $|\mathrm{t} /-| \mathrm{t} \mid$ & 14 & .178 & .680 & .013 & -76.621 & 6.888 \\
\hline & & $|\mathrm{t}|-|\mathrm{t}|$ & 14 & 4.722 & .047 & .252 & -74.474 & 34.741 \\
\hline & \multirow[t]{3}{*}{ F2_25\% } & $|\mathrm{t} /-| \mathrm{t} \mid$ & 14 & 1.964 & .183 & .123 & -205.286 & -33.247 \\
\hline & & $|\mathrm{t} /-| \mathrm{t} \mid$ & 14 & 38.018 & .000 & .731 & -222.895 & -114.572 \\
\hline & & $|\mathrm{t}|-|\mathrm{t}|$ & 14 & 26.766 & .000 & .657 & -131.938 & 33.005 \\
\hline & \multirow[t]{3}{*}{ F3_25\% } & $|\mathrm{t} /-| \mathrm{t} \mid$ & 14 & .200 & .662 & .014 & -33.012 & 198.612 \\
\hline & & $|\mathrm{t} /-| \mathrm{t} \mid$ & 14 & 2.440 & .141 & .148 & -98.208 & 74.741 \\
\hline & & $|t|-|t|$ & 14 & 3.345 & .089 & .193 & -204.843 & 15.776 \\
\hline
\end{tabular}

3.3.2. F2 at voicing onset and $25 \%$ of the following vowel. For F2 at voicing onset of the following vowel, there was a main effect of consonant, $F(2,28)=$ $28.682, p<.001$. There was no effect of prosodic context, nor was there a significant consonant*context interaction. The planned contrasts (see Table 6) showed that the dental $/ \mathrm{t} /$ was significantly different from $/ \mathrm{t} /$ and $/ \mathrm{t} /$ in the $/ \mathrm{aCa} /$ context. In the $/ \mathrm{a} \# \mathrm{Ca} / \mathrm{and} / \# \# \mathrm{Ca} /$ contexts, i.e., where the coronal consonants were word-initial, only /t/ and / $/ \mathrm{t} /$ differed, though the $/ \mathrm{t} / / \mathrm{t} / \mathrm{contrast}$ approached significance in $/ \# \# \mathrm{Ca} /, p=.01$. 
For $\mathrm{F} 2$ at $25 \%$ into the following vowel, there were significant main effects of consonant, $F(2,28)=36.777, p<.001$, and context, $F(1.448,20.272)=19.781$, $p<.001$. There was no significant consonant*context interaction. The planned contrasts (see Table 7) revealed that $\mathrm{F} 2$ at $25 \%$ into the following vowel differentiated $/ \mathrm{t} /$ from $/ \mathrm{t} /$ and $/ \mathrm{t} / \mathrm{in} / \mathrm{aCa} /$, while it differentiated $/ \mathrm{t} /$ from $/ \mathrm{t} /$ and $/ \mathrm{t} /$ in word-initial $/ \mathrm{a} \# \mathrm{Ca} /$ and importantly in utterance-initial $/ \# \# \mathrm{Ca} /$.

3.3.3. F3 at voicing onset and $25 \%$ of the following vowel. For F3 at voicing onset of the following vowel, there were significant main effects of consonant, $F(2,28)=13.835, p<.001$, and of context, $F(1.218,17.056)=4.789, p=.037$, and a significant consonant*context interaction, $F(4,56)=3.783, p=.009$. The planned contrasts (see Table 6) showed that F3 at voicing onset of the following vowel differentiated $/ \mathrm{t} /$ from $/ \mathrm{t} /$ in the $/ \mathrm{aCa} /$ context, and $/ \mathrm{t} /$ from both $/ \mathrm{t} /$ and $/ \mathrm{t} / \mathrm{in}$ the $/ \mathrm{a} \# \mathrm{Ca} /$ context. $\mathrm{F} 3$ did not, however, differentiate any consonant pair in the utterance-initial /\#\#Ca/ context.

For F3 at 25\% into the following vowel, there was a significant main effect of consonant type, $F(2,28)=7.135, p=.003$, but not of prosodic context. There was a significant interaction between consonant and context, $F(3.205,44.871)=7.086$, $p<.001$. The planned contrasts (see Table 7 ) showed that /t / was marginally differentiated from $/ \mathrm{t} /$ and $/ \mathrm{t} /$ in the $/ \mathrm{aCa} /$ context, but clearly so in the $/ \mathrm{a} \# \mathrm{Ca} /$ context. However, this measure did not differentiate any of the stops utterance-initially $(/ \# \# \mathrm{Ca} /$ context).

\section{Discussion}

The present paper investigated the acoustic differentiation of three coronal stops, dental $/ \mathrm{t} /$, alveolar $/ \mathrm{t} /$, and retroflex $/ \mathrm{t} /$, in the Indigenous Australian language Wubuy, which is unusual in reportedly maintaining the full coronal stop series word/utterance-initially as well as word-medially. In particular, we investigated whether these stops are differentiated in terms of the formant trajectories of adjoining vowels leading into the consonant and following the consonant release across three prosodic contexts, /aCa/, /a\#Ca/ and / $/ \# \mathrm{Ca} /$. Our aims were to determine how the acoustic correlates of the articulatory movement from the preceding vowel into consonant closure distinguish among / $\mathrm{t} /-\mathrm{t} / \mathrm{-} / \mathrm{t} /$ in Wubuy; whether and how the movement from consonant release into the following vowel may also distinguish among these consonants acoustically; and whether and how the formant transitions into the following vowel may distinguish among these three coronal stops even in word- and especially utterance-initial position.

With respect to the main effects of coronal place of articulation (POA) in the preceding vowel in $/ \mathrm{aCa}$ / and $/ \mathrm{a} \# \mathrm{Ca} /$ contexts, the results for both $\mathrm{F} 1$ and $\mathrm{F} 3$ at both $75 \%$ into the preceding vowel and at consonantal closure indicate that the mean formant frequencies for the three target coronal stops differ systematically 
across these two prosodic contexts. The formant measurements (Figure 2) and planned contrasts (summarized in Table 8), furthermore, support prior reports of F3 lowering for the retroflex /t/, relative to alveolar and dental stops (e.g., Hamilton 1996; Anderson 1997, 2000; Narayanan and Kaun 1999; Steriade 2001). However, the significant consonant type*context interaction at both measurement points for F3 indicates that its contribution to coronal differentiation in the preceding vowel formant transitions is reduced in the $/ \mathrm{a} \# \mathrm{Ca} /$ prosodic context relative to word-internal /aCa/ (see Table 8). Interestingly, our findings also identified a parallel pattern of $F 1$ lowering in the preceding vowel transitions for

Table 8. Overall significance table. The cell numbers refer to the significant p values obtained for each of the series of planned contrasts presented in Tables 5, 6, 7, 8. Note that $*$ indicates a marginally significant result. For the preceding vowel, alpha $=.0083$, for the following vowel, alpha $=.0055$.

\begin{tabular}{|c|c|c|c|c|c|c|}
\hline \multirow[t]{2}{*}{ Context } & \multirow[t]{2}{*}{ Measure } & \multirow[t]{2}{*}{ Contrast } & \multicolumn{2}{|c|}{ Preceding vowel } & \multicolumn{2}{|c|}{ Following vowel } \\
\hline & & & $75 \%$ & Closure & Onset & $25 \%$ \\
\hline \multirow[t]{9}{*}{$\mid \mathrm{aCa} /$} & \multirow[t]{3}{*}{ F1 } & $|\mathrm{t} /-| \mathrm{t} /$ & & & \multicolumn{2}{|l|}{.001} \\
\hline & & $|\mathrm{t} /-| \mathrm{t} /$ & .003 & .001 & & \\
\hline & & $|\mathrm{t} /-| \mathrm{t} \mid$ & .000 & .000 & \multicolumn{2}{|l|}{.000} \\
\hline & \multirow[t]{3}{*}{$\mathrm{F} 2$} & $|\mathrm{t} /-| \mathrm{t} \mid$ & & & .000 & .000 \\
\hline & & $|\mathrm{t} /-| \mathrm{t} \mid$ & & & .001 & .000 \\
\hline & & $|\mathrm{t} /-| \mathrm{t} \mid$ & & & & \\
\hline & \multirow[t]{3}{*}{ F3 } & $|\mathrm{t}|-|\mathrm{t}|$ & .006 & .001 & \multirow[t]{3}{*}{.002} & \multirow{3}{*}{$\begin{array}{l}.009^{*} \\
.006^{*}\end{array}$} \\
\hline & & $|\mathrm{t}|-|\mathrm{t}|$ & .000 & .000 & & \\
\hline & & $|\mathrm{t} /-| \mathrm{t} \mid$ & .000 & .000 & & \\
\hline \multirow[t]{8}{*}{ |a\#Ca/ } & \multirow[t]{3}{*}{ F1 } & \multirow{2}{*}{\multicolumn{5}{|c|}{$\begin{array}{l}|\mathrm{t} /-| \mathrm{t} \mid \\
\mid \mathrm{t} /\end{array}$}} \\
\hline & & & & & & \\
\hline & & $|\mathrm{t}|-|\mathrm{t}|$ & & & & .003 \\
\hline & \multirow[t]{3}{*}{$\mathrm{F} 2$} & $|\mathrm{t}|-|\mathrm{t}|$ & & & \multirow{3}{*}{.000} & \\
\hline & & $|\mathrm{t} /-/ \mathrm{t}|$ & & & & .000 \\
\hline & & $|t|-|t|$ & & & & .002 \\
\hline & \multirow[t]{2}{*}{ F3 } & $|\mathrm{t} /-| \mathrm{t} \mid$ & & .000 & \multirow{2}{*}{$\begin{array}{l}.001 \\
.000\end{array}$} & .000 \\
\hline & & $\begin{array}{l}|\mathrm{t} /-| \mathrm{t} \mid \\
|\mathrm{t} /-| \mathrm{t} \mid\end{array}$ & .000 & .002 & & .000 \\
\hline \multirow[t]{9}{*}{ |\#\#Ca/ } & \multirow[t]{3}{*}{$\mathrm{F} 1$} & $|\mathrm{t} /-| \mathrm{t} \mid$ & & & \multirow{9}{*}{$\begin{array}{l}.010^{*} \\
.000\end{array}$} & \multirow{9}{*}{$\begin{array}{l}.000 \\
.000\end{array}$} \\
\hline & & $|\mathrm{t} /-| \mathrm{t} \mid$ & & & & \\
\hline & & $|\mathrm{t}|-|\mathrm{t}|$ & & & & \\
\hline & \multirow[t]{3}{*}{$\mathrm{F} 2$} & $|\mathrm{t} /-| \mathrm{t} \mid$ & & & & \\
\hline & & $|\mathrm{t} /-| \mathrm{t} \mid$ & & & & \\
\hline & & $|\mathrm{t}|-|\mathrm{t}|$ & & & & \\
\hline & \multirow[t]{3}{*}{ F3 } & $|\mathrm{t} /-| \mathrm{t} \mid$ & & & & \\
\hline & & $|\mathrm{t} /-| \mathrm{t} \mid$ & & & & \\
\hline & & $|t|-|t|$ & & & & \\
\hline
\end{tabular}


the retroflex, which was unexpected and has not been reported previously. Such F1 lowering implies that raising of the tongue body and/or jaw is also a component of retroflex stop coarticulation with the preceding vowel (anticipatory coarticulation).

On the other hand, we found no significant F2 effects in the preceding vowel formant transitions for $/ \mathrm{aCa} /$ and $/ \mathrm{a} \# \mathrm{Ca} /$ in Wubuy. This is consistent with previous accounts of other Indigenous Australian languages, which have indicated that these three coronal stops are not reliably differentiated in the F2 of the preceding vowel transitions (Hamilton 1996; Anderson 1997).

However, our results for formant measures in the following vowel transitions are inconsistent with prior claims that the coronal stops fail to be reliably distinguished at the consonant release. Significant coronal POA differences were found in the formant transitions out of the consonant release in all three prosodic contexts, /aCa/, /a\#Ca/, and /\#\#Ca/. Specific coronal contrasts differed in F1, F2, and/ or F3 at either vowel onset or $25 \%$ into the vowel or both. Of particular interest is that F2 provides certain reliable distinctions among Wubuy coronal stops in the post-release vowel transitions, suggesting a contribution of front-back tongue body positioning. Altogether, these results are consistent with claims that Wubuy maintains the full series of coronal stop distinctions in all prosodic positions (Heath 1984).

These results thus provide novel evidence on two critical issues, both of which have important theoretical implications: 1) coronal stop place distinctions are reliably differentiated (by F1, F2, F3) in the vowel following consonantal release, and not only in the preceding vowel; and 2) neutralisation of word/utterance-initial apical stop contrasts (alveolar versus retroflex) is not universal across coronal-rich languages. The significant effect of prosodic context on post-release F1 at both measurement points and F3 at vowel onset, taken together with the significant interactions of consonant*context at both measurement points for F1 and F3, additionally suggest that coronal stop POA differentiation in the following vowel transitions decreases from the word-medial $/ \mathrm{aCa} /$ prosodic context to the word- and utterance-initial $/ \# \# \mathrm{Ca} /$ context. Notably, however, this pattern was not observed for F2, where there was a significant effect of context only at onset of the following vowel and no significant consonant*context interaction. These formant differences suggest that prosodic strengthening effects on Wubuy coronal production may primarily be due to adjustments in tongue/jaw height, affecting F1 in combination with the back-cavity affiliation of F3 for /a/ (Stevens 2000), rather than in tongue body fronting, affecting F2 - which differentiates coronal POA in the post-release formants regardless of prosodic context.

Taken from a broader perspective, our post-release F2 findings are consistent with more general patterns of acoustic differentiation across the grosser POA distinctions among velar, alveolar and labial stops, which suggest that place of articulation information is conveyed by differences in the F2 transition in the following vowel in /CV/ syllables (Pickett et al. 1995). The similarities we see 
here for coronal POA differentiation in following F2, therefore, add exciting new evidence suggesting this characteristic of post-release F2 transitions is a general principle of place of articulation differentiation, and does not exclude the coronal subclass.

Nonetheless, the results of the planned contrasts indicate that there are systematic asymmetries in the differentiation of Wubuy coronal stop POAs according to prosodic context, closure vs release transitions, formant, and consonant pair. The complex pattern of differentiation indicated by these planned contrasts is summarised in Table 8. In particular, there is statistical evidence of a reduction in consonant differentiation in the preceding vowel from $/ \mathrm{aCa} /$ to $/ \mathrm{a} \mathrm{Aa} /$.

Table 8 also illustrates that interpreting the formant patterns observed in the following vowel must take into account the prosodic context, given the clear evidence for some reduction in coronal POA differentiation in the context of a word boundary, as has been previously observed for other languages. A good example of the pattern of decreased coronal POA differentiation in this prosodic context is observed in the dental-alveolar contrast. This POA contrast is clearly differentiated by $\mathrm{F} 1, \mathrm{~F} 2$, and $\mathrm{F} 3$ in the following vowel in the $\mathrm{aCa}$ / context (where we recall that the targets /maata/ and /matal/ also differ word-finally), but only by F3 in the /a\#Ca/ context, and only marginally by F2 in the utterance-initial context of /\#\#Ca/. Importantly, however, our findings clearly contradict previous claims that vowel transitions from dentals and alveolars into the following vowel poorly differentiate these two coronal stop place distinctions.

A closer look at the planned comparisons nonetheless provides evidence for robust coronal POA differentiation in the post-release vowel formant transitions, as we move from $/ \mathrm{aCa} /$ to $/ \mathrm{a} \# \mathrm{Ca} /$ and $/ \# \# \mathrm{Ca} /$, for the reportedly fragile alveolarretroflex contrast. This contrast, which is frequently reported to neutralise in initial position in other coronal-rich languages, is differentiated in Wubuy only by F1 in the following vowel transitions in the word-medial /aCa/ context, while it is differentiated by both F1 and F2 in the word-initial but utterance-medial /a\#Ca/ context, and by F2 in the word- and utterance-initial /\#\#Ca/ context. Even though the target words /tawal/ and /tankalkara/ differ in the consonant that follows the vowel, the formant trajectories into that vowel (see Figure 2e) are inconsistent with a possible alternative that the F2 differences are due to the following consonants (/w/ vs $/ \mathrm{y} /$ ), because all three trajectories approach convergence at $75 \%$ into the following vowel. Thus it is clear that the alveolar-retroflex stop contrast does not neutralise articulatorily in initial positions in Wubuy. F2 evidence of this apical POA difference is available in the following vowel transitions, which could support perceptual differentiation in the two word-initial contexts of $/ \mathrm{a} \# \mathrm{Ca} /$ and $/ \# \# \mathrm{Ca} /$, but not in the word-medial context of $/ \mathrm{aCa} /$, where perceptual differentiation is not as problematic, as this context already provides ample evidence of coronal POA differences in the preceding vowel.

The differentiation of the dental and retroflex stops also indicates an effect of prosodic boundaries in this coronal place contrast. Specifically, this contrast is dif- 
ferentiated only by $\mathrm{F} 2$ in the following vowel in the $/ \mathrm{aCa} /$ context (where $\mathrm{F} 3$ is only marginally significant), while it is differentiated reliably by both F2 and F3 in the following vowel transitions in the /a\#Ca/ context, and remains differentiated by $\mathrm{F} 2$ in the absolute initial position of /\#\#Ca/.

The evidence for prosodic context effects on acoustic differentiation of the Wubuy coronal stops has more general theoretical implications as well. We find Articulatory Phonology a useful framework for considering possible articulatory bases for the prosodic strengthening effects we found. According to Articulatory Phonology (AP) (Browman and Goldstein [1992]; Saltzman and Munhall [1989]), the coordinated activation of constriction gestures by the vocal tract articulators (effectors: tongue tip, tongue body, lips, velum, and glottis) is achieved through a speech planning process that is driven by a specification of couplings among the participating gestures. Specifications for utterances are provided in 'coupling graphs' which provide the input to the speech planning process (Goldstein et al. 2006). The coupling graphs specify the relative phasing among pairs of articulatory gestures in a given utterance. In a coupling graph, the gestures by two or more effectors may be 'in-phase' (they are onset-aligned) or 'anti-phase' (they are peak-aligned) or they may be uncoupled. Findings from AP research suggest that consonant-vowel gestures are more tightly coupled (i.e., in-phase) for CV syllables than for VC syllables (i.e., anti-phase) (Nam et al. 2009), and that articulatory gestures increase in duration (Byrd et al. 2000; Byrd et al. 2006) and in (spatial) magnitude (Fougeron and Keating 1997; Byrd and Saltzman 1998; Tabain 2003b; Cho 2005; 2006) when a CV is aligned with a prosodic boundary (onset of a word, phrase, or sentence). There are several ways in which these AP considerations might begin to account for the prosodic context effects we found. ${ }^{3}$ First, the increased duration of a consonant gesture at a prosodic boundary might result in some of the increased POA differentiation we observed in the vowel transitions in the word- and utterance-initial CVs. Second, the increased magnitude of gestures that occurs at a prosodic boundary (prosodic strengthening) would likely also result in the increased acoustic effects we observed in wordand utterance-initial CVs. Third, the topology of the coupling graph could differ as a function of prosodic context. The within-word consonant could be coupled to both the preceding and following vowels, while the utterance initial consonants would be coupled only to the following vowel. In any case further empirical and modelling work would be required to evaluate these speculations about possible prosodic boundary effects on preceding and following vowel transitions. Any of these possibilities could lead to larger acoustic effects in the following vowel transitions when the CVs are word- and utterance-initial (\#\# $\underline{\mathrm{CV}}$ ), than when they are word-medial (VCV) (Byrd and Choi 2010), and conversely should result in greater acoustic differentiation of coronal POAs in the preceding vowel transitions (producing anticipatory coarticulation) when the VC occurs wordmedially (VCV) than when the $\mathrm{V}$ and $\mathrm{C}$ are separated by a prosodic boundary (V\#CV) (see Fowler and Saltzman 1993). Note, however, that the latter pattern 
is also compatible with psychoacoustics-based predictions (e.g., Steriade 2001). Conversely, the transitions into the following vowel (producing perseverant coarticulation) should be most clearly differentiated when the CV is wordand utterance-initial, and least clearly differentiated when it is word-medial. We observed essentially these patterns in our Wubuy data, suggesting that prosodic strengthening in / V\#CV/ and /\#\#CV/ contexts relative to / VCV/ contexts does indeed enhance coronal POA distinctions in the transitions into the following vowel. This could be particularly important for the maintenance of fragile contrasts such as the alveolar-retroflex contrast in Wubuy, and particularly in initial position.

To conclude, we find that the formant frequency patterns observed are consistent with reports that these Wubuy coronal stop POA contrasts are maintained across the three prosodic contexts examined here, including in word- and even utterance-initial position. This novel finding thus clarifies our understanding of the previously observed patterns of neutralisation of the apical contrast in coronal stops in studies of other Australian Indigenous languages, which our findings indicate must be language-specific rather than universal in nature.

We would like to also suggest, however, that the enhanced differentiation of these contrasts after the prosodic boundary in the $/ \mathrm{a} \# \mathrm{Ca} /$ and $/ \# \# \mathrm{Ca} /$ contexts may not be due to the place of articulation differences alone, a statically-defined property, but also to proposed dynamic differences in the articulation of the stops, particularly the retroflex. Such dynamic differences among the coronal stops could account for why the acoustic differentiation of the consonant only increases in the context of a prosodic boundary for some but not other contrasts. In particular, we suggest that the previously-posited forward-sweeping gesture of the (sublaminal) tongue tip in the case of the retroflex may result in greater overlap with the vowel, and thereby reveal more consonant POA information in the following vowel (Butcher 1993; Tabain 2003a; 2003b). This is consistent with the observed higher F2 values in our study. The fact that apico-retroflexes involve constriction locations that are different at onset and release can be inferred from the difference in F1 and F3 in the preceding versus the following vowel transition. ${ }^{4}$ Mean F1 is $360 \mathrm{~Hz}$ at the point of consonant closure (consonant onset) but $532 \mathrm{~Hz}$ at release; mean F3 is $2022 \mathrm{~Hz}$ at closure onset but 2900 at release, indicating a substantial change in tongue position between those two points in time. This difference between F1 and F3 at onset and release distinguishes retroflexes from the other two coronals examined here, which do not show such large differences in onset and release formant values (this difference is readily appreciable in Figures $2 \mathrm{a}-\mathrm{b}, 2 \mathrm{c}-\mathrm{d}$ above). Indeed, while F1 is significantly lowered in the preceding vowel, F2 is significantly raised in the following vowel for retroflexes, suggesting forward motion of the tongue, which may be achieved in part by the tongue body raising during consonant closure that is implied by the lowered F1 in the preceding vowel transitions. This lends support to the hypothesis that there 
is greater articulatory overlap with the following vowel for retroflexes than for other coronals as a forward sweeping gesture of the tongue tip for retroflexes presumably entails that, by the end of the down-sweep, a greater proportion of overall tongue mass has reached a position more anterior than that achieved by the other coronals.

In addition to the ways in which the formant trajectories differentiate the three Wubuy stops in the preceding and the following vowel, we hypothesize that other dynamic properties of consonantal closure and release, e.g., closure duration, timing of glottal pulsing relative to release (voice onset time: VOT), and burst spectrum, also contribute to the reliable differentiation of these three Wubuy coronal contrasts in utterance-initial positions. These additional distinctions may thus also help maintain the contrasts both synchronically and diachronically, as BundgaardNielsen, Baker et al. (2010) noted and as reported for other languages, e.g. by Anderson and Maddieson (1994) for Tiwi and Anderson (2000) for Western Arrernte, among others.

The systematic acoustic differentiation of formant transitions for the three Wubuy coronal stops dental $/ \mathrm{t} /$, alveolar $/ \mathrm{t} /$, and retroflex $/ \mathrm{t} /$ reported here of course also invites further study in at least two additional directions. Naturally, further investigations of the acoustic and articulatory differentiation of Wubuy coronal stop places in other vowel contexts are desirable, as are investigations of the acoustic and articulatory properties of Wubuy coronal nasal and lateral place distinctions (see preliminary report by Best et al. 2010). Secondly, the identification of measurable acoustic differences in these stops across three prosodic contexts invites a rigorous investigation of how well these stops are perceptually differentiated by native speakers of Wubuy in the three contexts examined here (see preliminary report by Bundgaard-Nielsen and Baker 2011), in conjunction with discriminant analysis of the various acoustic measurements of both vowels and consonants.

\section{Acknowledgements}

The authors would like to thank the Wubuy participants, LM, JN, JT, DU, and their families, in particular MU, for their participation in this research project. We also thank the anonymous reviewers, Louis Goldstein, and editors Ian Maddieson and Caroline Smith, as well as the audience at the University of Melbourne, for their comments and insights. Finally, we thank the University of Western Sydney, the University of Newcastle, and the University of New England for providing the necessary funding for us to undertake this project. The research was approved by the University of Western Sydney Human Research Ethics Committee. 


\section{Appendix}

Table 9. Mean F1, F2, and F3 measurements at 75\% into the preceding vowel, at consonantal closure, onset of the following vowel, and $25 \%$ into the following vowel.

\begin{tabular}{|c|c|c|c|c|c|c|c|c|c|c|}
\hline \multirow[t]{2}{*}{ Context } & \multirow[t]{2}{*}{ Formant } & \multirow[t]{2}{*}{ Consonant } & \multicolumn{4}{|c|}{ Preceding vowel } & \multicolumn{4}{|c|}{ Following vowel } \\
\hline & & & $75 \%$ & SD & closure & SD & Onset & SD & $25 \%$ & SD \\
\hline \multirow[t]{9}{*}{ /aCa/ } & \multirow[t]{3}{*}{ F3 } & $\mid \mathrm{t} /$ & 2904 & 228 & 2989 & 198 & 3076 & 136 & 3032 & 164 \\
\hline & & $|\mathrm{t}|$ & 2747 & 269 & 2588 & 341 & 2712 & 379 & 2769 & 384 \\
\hline & & |t/ & 2158 & 202 & 2022 & 177 & 2900 & 342 & 2906 & 195 \\
\hline & \multirow[t]{3}{*}{$\mathrm{F} 2$} & $\mid \mathrm{t} /$ & 1520 & 419 & 1811 & 134 & 1659 & 126 & 1611 & 89 \\
\hline & & $\mid t /$ & 1675 & 216 & 1751 & 230 & 1923 & 69 & 1788 & 116 \\
\hline & & /t/ & 1724 & 147 & 1765 & 219 & 1878 & 155 & 1841 & 99 \\
\hline & \multirow[t]{3}{*}{ F1 } & $\mid \mathrm{t} /$ & 702 & 124 & 469 & 70 & 568 & 65 & 676 & 105 \\
\hline & & $|t|$ & 731 & 118 & 482 & 59 & 496 & 74 & 643 & 102 \\
\hline & & /t/ & 598 & 69 & 360 & 40 & 532 & 95 & 659 & 102 \\
\hline \multirow{9}{*}{ /a\#Ca/ } & \multirow[t]{3}{*}{ F3 } & $\mid \mathrm{t} /$ & 3037 & 69 & 3081 & 131 & 3149 & 71 & 3127 & 260 \\
\hline & & $\mid \mathrm{t} /$ & 2956 & 160 & 2867 & 135 & 2788 & 300 & 2929 & 283 \\
\hline & & $\mid \mathrm{t} /$ & 2669 & 298 & 2677 & 382 & 2772 & 200 & 2798 & 221 \\
\hline & \multirow[t]{3}{*}{$\mathrm{F} 2$} & $\mid \mathrm{t} /$ & 1855 & 89 & 1887 & 108 & 1712 & 90 & 1458 & 226 \\
\hline & & $\mid \mathrm{t} /$ & 1800 & 157 & 1907 & 102 & 1855 & 223 & 1576 & 202 \\
\hline & & $\mid \mathrm{t} /$ & 1796 & 133 & 1881 & 95 & 1873 & 122 & 1746 & 93 \\
\hline & \multirow[t]{3}{*}{ F1 } & $\mid \mathrm{t} /$ & 715 & 118 & 497 & 171 & 561 & 70 & 748 & 68 \\
\hline & & $\mid \mathrm{t} /$ & 662 & 115 & 496 & 187 & 560 & 132 & 779 & 58 \\
\hline & & $|\mathrm{t}|$ & 666 & 119 & 446 & 142 & 576 & 103 & 692 & 76 \\
\hline \multirow[t]{9}{*}{ |\#\#Ca/ } & \multirow[t]{3}{*}{ F3 } & $|\mathrm{t}|$ & & & & & 3046 & 153 & 2781 & 288 \\
\hline & & $\mid \mathrm{t} /$ & & & & & 2963 & 182 & 2748 & 248 \\
\hline & & $\mid \mathrm{t} /$ & & & & & 3058 & 99 & 2897 & 240 \\
\hline & \multirow[t]{3}{*}{ F2 } & $\mid \mathrm{t} /$ & & & & & 1679 & 143 & 1457 & 141 \\
\hline & & $\mid \mathrm{t} /$ & & & & & 1798 & 189 & 1539 & 115 \\
\hline & & $\mid \mathrm{t} /$ & & & & & 1847 & 94 & 1795 & 140 \\
\hline & \multirow[t]{3}{*}{$\mathrm{F} 1$} & $\mid \mathrm{t} /$ & & & & & 624 & 42 & 739 & 57 \\
\hline & & |t $/$ & & & & & 639 & 65 & 766 & 46 \\
\hline & & |t $/$ & & & & & 659 & 73 & 732 & 42 \\
\hline
\end{tabular}

Correspondence e-mail address: r.bundgaardnielsen@uws.edu.au bjbaker@unimelb.edu.au c.kroos@uws.edu.au mark.harvey@newcastle.edu.au c.best@uws.edu.au 


\section{Notes}

1. Heath (1984: 12) says "Hearing the distinction clearly [i.e. between apico-alveolar and apicoretroflex] requires a preceding vowel, so the two series are effectively indistinguishable following a stop, nasal, or liquid." Heath does not directly discuss the effect of utterance-initial context on the apical distinction.

2. We also recorded a fourth speaker. This participant had chiefly spoken English since she was a young woman, was married to a native English speaker, and her principal residence was in a large urban centre rather than in Numbulwar. As a result, she appeared over time likely to have become English-dominant, though she reported using Wubuy alongside English in her everyday life, to other Wubuy speakers in her community and occasionally to her children and grandchildren. Because of the possibility that acquired L2-English dominance could have influenced her production of non-English coronals, she was not included the present analyses.

3. We thank Louis Goldstein for guidance on these aspects of Articulatory Phonology, and for his suggestions on how they might account for prosodic context effects on vowel transition acoustics.

4. We thank the editors for alerting us to the significance of this observation.

\section{References}

Anderson, Victoria B. 1997. The perception of coronals in Western Arrernte. In George Kokkinakis (ed.) Proceedings of Eurospeech 97, 389-392. Rhodes: University of Patras.

Anderson, Victoria B. 2000. Giving weight to phonetic principles: The case of place of articulation in Western Arrernte. Ph dissertation, University of California, Los Angeles. http://www2.hawaii.edu/ $\sim$ vanderso/AndersonDiss.pdf. Accessed January 312012.

Anderson, Victoria B. and I. Maddieson (1994). Acoustic Characteristics of Tiwi Coronal Stops. UCLA Working Papers in Phonetics. 87:131-162.

Baker, Brett J. 2008. The interpretation of complex nominal expressions in Southeast Arnhem Land languages. In Ilana Mushin \& Brett J. Baker (eds.), Discourse and grammar in Australian languages, 135-166. Philadelphia \& Amsterdam: Benjamins.

Best, Catherine T., Rikke L. Bundgaard-Nielsen, Christian Kroos, Mark Harvey, Brett Baker, Louis Goldstein \& Mark Tiede. 2010. How does a language contrast four distinct coronal stop places? Differentiation of lingual gestures by speakers of Wubuy (Australia). Poster presented at LabPhon12, Albuquerque NM, 8-10 July.

Boersma, Paul \& David Weenink. 2007. PraAt: Doing phonetics by computer [computer program]. Version 5.1.05, retrieved 21 September 2008 from http://www.PraAt.org/.

Bradley, David. 1980. Acoustic correlates of seven consonant positions in Yanyuwa. Working Papers in Linguistics 6. 21-48. Melbourne: Melbourne University Department of Linguistics.

Browman, Catherine P. \& Louis Goldstein. 1989. Articulatory gestures as phonological units. Phonology 6. 201-251.

Browman, Catherine P. \& Louis Goldstein. 1992. Articulatory phonology: An overview. Phonetica 49(3-4). 155-180.

Bundgaard-Nielsen, Rikke L. \& Brett Baker. 2011. The perception and production of Wubuy coronal stops. Paper presented at the $10^{\text {th }}$ Australian Languages Workshop, Stradbroke Island, 11-13 March.

Bundgaard-Nielsen, Rikke L., Brett Baker, Mark Harvey, Christian Kroos \& Catherine T. Best. 2010a. Co-option of ancillary articulatory parameters in the prevention of near-neutralisation of multiple coronals. Paper presented at the International Conference for Acoustics [ICA], Sydney, 23-25 August. 
Bundgaard-Nielsen, Rikke L., Christian Kroos, Mark Harvey, Catherine T. Best, Brett Baker \& Louis Goldstein. 2010b. A kinematic analysis of temporal differentiation of the four-way coronal stop contrast in Wubuy (Australia). In Marija Tabain, Janet Fletcher, David Grayden, John Hajek and Andy Butcher (eds.) Proceedings of the $13^{\text {th }}$ Australasian International Conference on Speech Science and Technology [SST] 2010 Melbourne, Australia, 14-16 December.

Butcher, Andrew. 1993. The phonetics of Australian languages. Ms. Adelaide: Flinders University, MS.

Butcher, Andrew. 1995. The phonetics of neutralisation: the case of Australian coronals. In Jack Windsor-Lewis (ed.), Studies in English \& general phonetics: essays in honour of Professor J. D. O'Connor, 10-38. London: Routledge.

Butcher, Andrew \& Marija Tabain. 2004. On the back of the tongue: Dorsal sounds in Australian languages. Phonetica 61. 22-52.

Byrd, Dani \& Susie Choi. 2010. At the juncture of prosody, phonology, and phonetics - The interaction of phrasal and syllable structure in shaping the timing of consonant gestures. In Cécile Fougeron, Barbara Kühnert, Mariapaola D'Imperio, Nathalie Vallée (eds.), Laboratory Phonology 10, 31-60. Berlin: de Gruyter Mouton.

Byrd, Dani, Abigail Kaun, Shrikanth Narayanan \& Elliot Saltzman. 2000. Phrasal signatures in articulation. In Michael B. Broe and Janet B. Pierrehumbert (eds.), Papers in Laboratory Phonology V. Acquisition and the lexicon, 70-87. Cambridge: Cambridge University Press.

Byrd, Dani, Jelena Krivokapić \& Sungbok Lee. 2006. How far, how long: On the temporal scope of phrase boundary effects. Journal of the Acoustical Society of America 120. 1589-1599.

Byrd, Dani \& Elliot Saltzman. 1998. Intragestural dynamics of multiple phrasal boundaries. Journal of Phonetics 26. 173-199.

Cho, Taehong. 2005. Prosodic strengthening and featural enhancement: Evidence from acoustic and articulatory realizations of /a,i/ in English. Journal of the Acoustical Society of America 117. 38673878.

Cho, Taehong. 2006. Manifestation of prosodic structure in articulation: Evidence from lip kinematics in English. In Louis Goldstein, Doug H. Whalen \& Catherine Best (eds.), Laboratory phonology 8: Varieties of phonological competence, 519-548. Berlin: Mouton de Gruyter.

Dart, Sarah N. 1991. Articulatory and acoustic properties of apical and laminal articulation. Los Angeles, CA: UCLA PhD Dissertation. Distributed as UCLA Working Papers in Phonetics 79.

Dart, Sarah N. \& Paroo Nihilani. 1999. The articulation of Malayalam coronal stops and nasals. Journal of the International Phonetic Association 29. 129-142.

Dixon, Robert M. W. 1980. The languages of Australia. Cambridge: Cambridge University Press.

Dorman, Michael \& Philipos C. Loizou. 1996. Relative spectral change and formant transitions as cues to labial and alveolar place of articulation. Journal of the Acoustical Society of America 100. 38253830.

Evans, Nicholas. 1985. Kayardild: The language of the Bentinck Islanders of north-west Queensland. Canberra, ACT: Australian National University PhD thesis.

Fougeron, Cécile \& Patricia A. Keating. 1997. Articulatory strengthening at edges of prosodic domains. Journal of the Acoustical Society of America 101.3728-3740.

Fowler, Carol A. \& Elliot Saltzman. 1993. Coordination and coarticulation in speech production. Language \& Speech 36. 171-195.

Goldstein, Louis, Dani Byrd \& Elliot Saltzman. 2006. The role of vocal tract gestural action units in understanding the evolution of phonology. In Michael A. Arbib (ed.), Action to language via the mirror neuron system, 215-249. Cambridge: Cambridge University Press.

Hamann, Silke. 2003. The phonetics and phonology of retroflexes. Utrecht: Utrecht Institute of Linguistics.

Hamilton, Philip. 1996. Phonetic constraints and markedness in the phonotactics of Australian Aboriginal languages. Toronto: University of Toronto $\mathrm{PhD}$ dissertation.

Harris, John. 1986. Northern Territory pidgins and the origin of Kriol. Canberra: Pacific Linguistics. 
Harvey, Mark. 2003. An initial reconstruction of Proto Gunwinyguan phonology. In Nicholas Evans (ed.), The non-Pama-Nyungan languages of northern Australia: Comparative studies of the continent's most linguistically complex region, 205-268. Canberra: Pacific Linguistics.

Heath, Jeffrey. 1978. Linguistic diffusion in Arnhem Land. Canberra: Australian Institute of Aboriginal Studies.

Heath, Jeffrey. 1982. Dictionary of Nunggubuyu. Canberra: Australian Institute of Aboriginal Studies.

Heath, Jeffrey. 1984. Functional grammar of Nunggubuyu. Canberra: Australian Institute of Aboriginal Studies.

Heath, Jeffrey. 1986. Syntactic and lexical aspects of nonconfigurationality in Nunggubuyu (Australia). Natural Language and Linguistic Theory 4. 375-408.

Henderson, John. 1998. Topics in Eastern and Central Arrernte grammar. Perth, WA: University of Western Australia PhD thesis.

Ladefoged, Peter. 2001. Vowels and consonants: An introduction to the sounds of languages. Oxford: Blackwell.

Ladefoged, Peter \& Ian Maddieson. 1996. The sounds of the world's languages. Oxford: Blackwell.

Leeding, Velma. 1989. Anindilyakwa phonology and morphology. Sydney, NSW: University of Sydney $\mathrm{PhD}$ thesis.

Liberman, Alvin M., Franklin S. Cooper, Donald P. Shankweiler, and Michael Studdert-Kennedy. 1967. Perception of the speech code. Psychological Review 74. 431-461.

Maddieson, Ian. 1997. Phonetic universals. In William J. Hardcastle and John Laver (eds.), The handbook of phonetic sciences, 619-639. Oxford: Blackwell.

Munro, Jennifer. 2005. Substrate language influence in Kriol: The application of transfer constraints to language contact in northern Australia. Armidale, NSW: University of New England PhD thesis.

Nam, Hosung, Louis Goldstein \& Elliot Saltzman. 2009. Self-organization of syllable structure: A coupled oscillator model. In François Pellegrino, Edigio Marsico, Ioana Chitoran \& Christophe Coupé (eds.), Approaches to phonological complexity, 299-328. Mouton de Gruyter: New York.

Narayanan, Shrikanth \& Abigail Kaun. 1999. Acoustic modeling of Tamil retroflex liquids. In Proceedings of the 14th International Congress of the Phonetic Sciences [ICPHS], San Francisco, CA, August. 2097-2100

Pickett, J. M., H. Timothy Bunnell \& Sally G. Revoile. 1995. Phonetics of intervocalic consonant perception: retrospect and prospect. Phonetica 52(1). 1-40.

Recasens, Daniel \& Aina Espinosa. 2009. An articulatory investigation of lingual coarticulatory resistance and aggressiveness for consonants and vowels in Catalan. Journal of the Acoustical Society of America 125(4). 2288-2298.

Saltzman, Elliot. L. \& Kevin G. Munhall. 1989. A dynamical approach to gestural patterning in speech production. Ecological Psychology 1(4). 333-382.

Sandefur, John. 1979. An Australian creole in the Northern Territory: A description of NgukurrBamyili dialects (Part 1). Darwin, NT: Summer Institute of Linguistics, Australian Aborigines Branch.

Smits, Roel, Louis ten Bosch \& René Collier. 1996. Evaluation of various sets of acoustical cues for the perception of prevocalic stop consonants: 1. Perception experiment. Journal of the Acoustical Society of America 100. 3852-3864.

Steriade, Donca. 2001. Directional asymmetries in place assimilation: A perceptual account. In Elizabeth Hume and Keith Johnson (eds.), The role of speech perception in phonology, 219-250. San Diego, CA: Academic Press.

Stevens, Kenneth N. 2000. Acoustic phonetics. Cambridge, MA: MIT Press.

Stokes, Judith. 1981. Anindilyakwa phonology from phoneme to syllable. In Bruce Waters (ed.), Australian phonologies: Collected papers, 138-181. Darwin, NT: Summer Institute of Linguistics, Australian Aborigines Branch. 
Tabain, Marija. 2003a. Effects of prosodic boundary on /aC/ sequences: Acoustic results. Journal of the Acoustical Society of America 113. 516-531.

Tabain, Marija. 2003b. Effects of prosodic boundary on /aC/ sequences: Articulatory results. Journal of the Acoustical Society of America 113. 2834-2849.

Tabain, Marija \& Andrew Butcher. 1999. Stop consonants in Yanyuwa and Yindjibarndi: Locus equation data. Journal of Phonetics 27. 333-357.

Werker, Janet F., John H. V. Gilbert, Keith Humphrey \& Richard C. Tees. 1981. Developmental aspects of cross-language speech perception. Child Development 52. 349-355.

Werker, Janet F. \& Chris E. Lalonde. 1988. Cross-language speech perception: Initial capabilities and developmental change. Developmental Psychology 24. 673-683. 

Copyright of Laboratory Phonology is the property of De Gruyter and its content may not be copied or emailed to multiple sites or posted to a listserv without the copyright holder's express written permission. However, users may print, download, or email articles for individual use. 